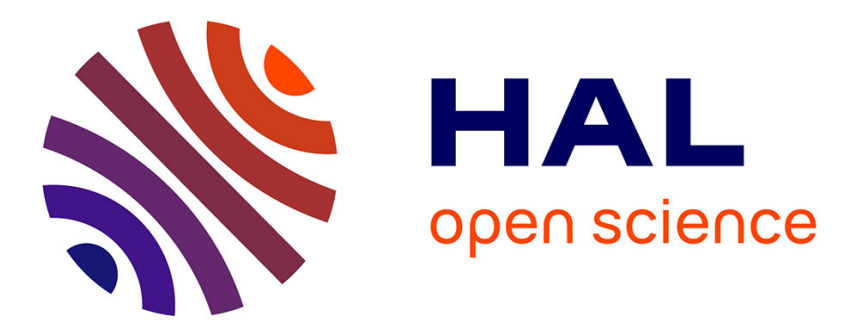

\title{
Multitemporal analysis of hydrological soil surface characteristics using aerial photos: A case study on a Mediterranean vineyard
}

Christina Corbane, Frédéric Jacob, Damien Raclot, Jean Albergel, Patrick Andrieux

\section{To cite this version:}

Christina Corbane, Frédéric Jacob, Damien Raclot, Jean Albergel, Patrick Andrieux. Multitemporal analysis of hydrological soil surface characteristics using aerial photos: A case study on a Mediterranean vineyard. International Journal of Applied Earth Observation and Geoinformation, 2012, 18, pp.356-367. 10.1016/j.jag.2012.03.009 . hal-03410127

\section{HAL Id: hal-03410127 \\ https://hal.science/hal-03410127}

Submitted on 31 Oct 2021

HAL is a multi-disciplinary open access archive for the deposit and dissemination of scientific research documents, whether they are published or not. The documents may come from teaching and research institutions in France or abroad, or from public or private research centers.
L'archive ouverte pluridisciplinaire HAL, est destinée au dépôt et à la diffusion de documents scientifiques de niveau recherche, publiés ou non, émanant des établissements d'enseignement et de recherche français ou étrangers, des laboratoires publics ou privés.

\section{(c) (1) $\$$}

Distributed under a Creative Commons Attribution - NonCommerciall 4.0 International 
We propose a classification for monitoring hydrological soil surface characteristics (H-SSC) in vineyards.

This multitemporal classification relies on expert knowledge about possible H-SSC transitions.

As compared to a monotemporal approach, it improved discrimination of $\mathrm{H}-\mathrm{SSC}$ related to crusting processes.

It also allowed detecting soil management practices such as mechanical and chemical weeding. 
1 Multitemporal analysis of hydrological soil surface characteristics using aerial photos: a case 1
2 study on a Mediterranean vineyard.

3

4 Christina Corbane ${ }^{1,2 *}$, Frédéric Jacob ${ }^{1}$, Damien Raclot ${ }^{1}$, Jean Albergel ${ }^{1}$, Patrick Andrieux ${ }^{3}$

5

$6 \quad{ }^{1}$ IRD, UMR LISAH INRA - IRD - SupAgro, 2 place Viala, 34060 Montpellier Cedex 1, France

7

$8{ }^{2}$ Current affiliation: European Commission, Joint Research centre, Via E. Fermi 2749, I-21027 Ispra 9 (VA) Italy

10

$11{ }^{3}$ INRA, UMR LISAH INRA - IRD - SupAgro, 2 place Viala, 34060 Montpellier Cedex 1, France

12

13 E-Mails: christina.corban@jrc.ec.europa.eu; frederic.jacob@supagro.inra.fr;

14 damien.raclot@supagro.inra.fr; jean.albergel@ird.fr; patrick.andrieux@,supagro.inra.fr

15

$16 *$ Author to whom correspondence should be addressed: christina.corban@jrc.ec.europa.eu,

$17 \quad$ Tel.: +390332789651 
Soil surface characteristics (SSC) constitute an important land surface property that drives the partitioning between infiltration and runoff. Therefore, knowledge of SSC is crucial for runoffforecasting in hydrology. However, the difficulties in measuring spatial variabilities and temporal dynamics of SSC have limited the use of this property in operational hydrology at the catchment on the basis of remotely sensed spectral and spatial information only.

The objective of the current study was to propose a multitemporal classification that integrates a priori information about possible $\mathrm{H}-\mathrm{SSC}$ evolutions, such as it is possible improving their characterization. H-SSC evolutions could be either natural, depending on rainfall events, or anthropogenic, driven by soil management practices. Knowledge of possible H-SSC evolutions was translated in the form of decision rules. It was applied to a time series of $\mathrm{H}-\mathrm{SSC}$ class maps derived from a monotemporal classification of monthly aerial photos. As compared to the monotemporal classification, the multitemporal classification had two advantages for the identification of H-SSC classes. First, it allowed improving the discrimination of classes related to crusting processes, with increased performances between 35 and $48 \%$ relative. Second, it was able to detect H-SSC temporal evolutions in relation to soil management practices. 


\section{INTRODUCTION}

Soil surface characteristics (SSC) are currently among the best available indicators for soil structural stability and partitioning between infiltration and runoff. Therefore, SSC knowledge gives partial evidence about catchment production function and erosion magnitude, which is essential for hydrological modelling (Auzet et al., 2001; Cerdan et al., 2001; Jetten et al., 1996; Liu et al., 2003). Within farmed Mediterranean catchments, the dominant influence of SSC has already been demonstrated for overland flows (Moussa et al. 2002) and pesticide transport (Lennartz et al., 1997; Louchart et al., 2001). In the context of operational hydrology at the catchment extent, it is therefore necessary monitoring SSC spatiotemporal variabilities in relation to anthropogenic and natural forcing.

In vineyard fields, the crucial role of SSC on infiltration rates was tested and validated under simulated rainfalls by Léonard and Andrieux (1998). By combining usual SSC attributes, Andrieux et al. (2001) proposed a typology of hydrological SSC (H-SSC) classes, where the classes correspond to distinct infiltration rates for Mediterranean cultivated areas without cracking soils. These usual SSC attributes were related to (i) surface crusting such as structural and sedimentary crust (Boiffin and Monier, 1986), (ii) stoniness (Poesen et al., 1990), (iii) micro-topography such as soil roughness which depends upon soil treatment (Lelong et al., 1993), and (iv) soil cover such as mulching, organic litter density and vegetation cover (Dunne and Dietrich, 1980).

The spatial heterogeneity of H-SSC was assessed in Mediterranean vineyards by Corbane et al. (2008a) who showed that H-SSC depicted considerable variability between rows and inter-rows. This was ascribed to the coupling effect between local topography, vegetation row structure, rainfall / runoff characteristics and soil management practices. This strong spatial variability, to be taken into account during field surveys of $\mathrm{H}-\mathrm{SSC}$, makes the latter labour intensive and costly. Thus, H-SSC monitoring requires alternative methods that compromise both a fine spatial resolution to capture spatial heterogeneities and the catchment extent to address operational hydrology. 
Remote sensing is the most promising technique to monitor H-SSC in a spatially distributed

manner, where satellite or aerial imagery can collect spatial and temporal information at the catchment extent with fine spatial resolution. Remote sensing techniques were successfully used for the retrieval of surface roughness (Baghdadi et al., 2002), humidity (Wang et al., 1997) and soil organic matter (Wiegand et al., 1992), especially under specific conditions such as bare soil or sparse vegetation. Later, relationships between reflectance and surface crusting (Goldshleger et al., 2002; Ben-Dor et al., 2003; 2004; Goldshleger et al., 2004) or infiltration rates (Goldshleger et al., 2001; 2002) were highlighted for bare soil conditions only. Overall, most studies have focused on single SSC attributes. However, infiltration / runoff partitioning are conditioned by a combination of several SSC attributes (Descroix et al., 2001; 2002), as taken into account by the H-SSC typology of Andrieux et al. (2001).

Among the remote sensing studies that addressed hydrological SSC (H-SSC), Wassenaar et al. (2005) investigated the potential of multiangular information at very high spatial resolution over Mediterranean vineyards. They showed several H-SSC could be distinguished (e.g., crusted mineral soil surfaces or half to fully covered surfaces with litter and / or weed), although some of them remained difficult to discriminate due to the influences of illumination and viewing conditions. Later, Corbane et al. (2008b) demonstrated that several classes could be distinguished on the basis of spectral and spatial information collected with aerial photographs. The method proposed by Corbane et al. (2008b) relied on an object-oriented multiscale classification that links H-SSC observed in the field to image-objects identified with an image segmentation process. The use of spatial information partially allowed overcoming inconsistent discriminations of H-SSC induced by similar spectral behaviours. Overall, several H-SSC classes still are difficult to separate with the monotemporal methods discussed above, where the monotemporal dimension refers to separately analysing each image independently from any chronological order of acquisition.

Given the current limitations of the H-SSC monotemporal classifications presented above, two main improvements can be foreseen. The first one relies on using richer spectral information, since spectroscopy (Bartholomeus et al., 2007; 2011) and hyperspectral imagery (Ben-Dor et al., 2002; 
100 Lagacherie et al., 2008; Weber et al., 2008) have provided promising results for characterizing 101 physicochemical properties of soil surface, including crusts (de Jong et al., 2011). A second 102 improvement relies on incorporating a priori information about H-SSC evolution, where using aerial 103 cameras with few spectral bands is attractive for operational hydrology at the watershed extent. The 104 current paper investigates this second way of improvement.

A priori information about the temporal evolution of land surface characteristics has been successfully used for classification purposes. It has taken form of expert knowledge or ancillary databases, where the associated uncertainties required using probabilistic approaches. Matrices of probable state transition were used by Janssen and Middelkoop (1992) who designed a knowledgebased classifier that integrated crop information for current and past years. Largouet and Cordier (2001) developed a probabilistic classification that relied upon (i) time dependencies of classes derived from a satellite image sequence, (ii) knowledge about the field locations and (iii) expertise on possible land-cover evolutions. Raclot et al. (2005) proposed a per-field land-cover classification, where a rule-based decision system incorporated yearly satellite imagery acquired during the growing period along with ancillary data such as cropping history (inter-annual crop rotations), context (altitude, soil type) and structure (field sizes and shapes). Mota et al. (2007) integrated temporal class dependencies by means of a transition diagram based on fuzzy possibility values, in order to classify land use and land cover. Lucas et al. (2007) implemented temporal decision rules based on fuzzy logic for mapping semi-natural habitats and agricultural land cover during an annual cycle. Overall, these multitemporal methods allowed improving performances as compared to monotemporal methods, although they depended upon complex modelling for handling temporal relationships.

In order to provide an efficient remote sensing monitoring of H-SSC for the benefit of operational hydrology at the catchment extent, the current study aims to propose and assess a multitemporal image classification that incorporates a priori information about $\mathrm{H}$-SSC temporal evolutions. A priori information consisted in expert knowledge about possible evolutions of H-SSC classes, in relation to environmental conditions (i.e., rainfall regime) and soil management practices. 
128 This expert knowledge was found in field and laboratory experiments that focused on the monitoring 129 of H-SSC under natural or simulated rainfalls, as reviewed by Pare et al. (2011). Focusing on 130 Mediterranean vineyards, the proposed method is applied to a time series of H-SSC class maps, where 131 the latter are beforehand derived from a monotemporal classification of monthly aerial photos. The 132 benefit of incorporating a priori information about H-SSC temporal evolution is evaluated by 133 comparing performances of multitemporal and monotemporal classifications. 134 135 136 137 21

\section{STUDY BACKGROUND: TYPOLOGY OF HYDROLOGICAL SSC (H-SSC)}

Among the various definitions suggested in the literature for characterizing SSC, we focused in the current study on the typology of hydrological SSC (H-SSC) proposed by Andrieux et al. (2001). This typology is devoted to Mediterranean vineyards. It combines usual SSC attributes. It was established according to field measurements of infiltration rates from Léonard and Andrieux (1998).

The SSC attributes to be selected because of their significant influence on infiltration as observed within Mediterranean vineyards are soil micro-topography, surface crusting (structural and sedimentary crust), soil cover (grass, mulching and organic litter), and stoniness. The typology disregards some usual SSC attributes (i.e., soil moisture, soil clay content and soil organic matter); since Leonard and Andrieux (1998) demonstrated their influences are of second order for 147 Mediterranean vineyards. The typology also disregards cracks that are not systematic in Mediterranean 148 vineyards, as in the case of the study area we considered here (Section 4.1).

For the selected SSC attributes, the typology relies on the following distinctions. Soil micro151 topography of tilled surfaces is determined by considering four classes of soil clod size: (i) lower than $1521 \mathrm{~cm}$, (ii) from 1 to $5 \mathrm{~cm}$, (iii) from 5 to $10 \mathrm{~cm}$, and (iv) larger than $10 \mathrm{~cm}$. A distinction is also 153 conducted between (i) clods of a recently tilled soils that can be clearly individualized, (ii) clods with a 154 slightly formed thin structural crust and (iii) tilled soil surfaces slightly sealed by raindrop impacts. 
155 Two types of surface crusts are distinguished, structural and sedimentary crust. Soil cover is 156 characterized using vegetation and litter fraction cover, with a thresholding of $50 \%$.

\section{A NEW KNOWLEDGE-BASED MULTITEMPORAL CLASSIFICATION OF H-SSC}

We propose here a new multitemporal classification that aims to provide $\mathrm{H}-\mathrm{SSC}$ maps as accurate as possible. For this, the proposed method analyses pairs of consecutive H-SSC class maps within a time series by integrating expert knowledge about possible H-SSC evolutions in accordance to ancillary information about daily rainfall. This multitemporal classification is designed for Mediterranean vineyards where $\mathrm{H}-\mathrm{SSC}$ evolutions are driven by two types of soil management practices (mechanical and chemical weeding) combined with rainfall forcing. Then, the proposed method must be able to detect these management practices that are supposed to impact significantly H-SSC evolutions. Besides, the time delay between two consecutive maps within the time series must hold with the HSSC dynamics, which is presumably close to the monthly timescale.

The proposed multitemporal classification consists of correcting H-SSC class maps, previously derived from any monotemporal classification, where maps are pixel or image-object based. The flowchart of the multitemporal classification is displayed in Figure 1. The first step is the design of the rule-based system that defines the possible H-SSC successors in accordance with expert knowledge about H-SSC evolutions (Section 3.1). The second step is the comparative analysis of the 
183 H-SSC successors against the output of the monotemporal classification (Section 3.2). This second 184 step is twofold. By considering the field scale that corresponds to soil management practices 185 (Section 3.3.1); the dominant H-SSC evolution is first identified. The monotemporal classification is 186 next corrected when it is inconsistent with the dominant evolution at the field scale (Section 3.2.2).

[Figure 1 about here]

In addition to its capability in generating time series of reliable H-SSC maps, the method we propose here also detects evolution drivers between natural and anthropogenic, including an identification of soil management practices between mechanical and chemical weeding. We detail hereafter each step of the proposed multitemporal classification.

\subsection{Expert knowledge on possible H-SSC evolutions}

The underlying concept is derived from recurrent in-situ observations of similar evolutions for various surface crusts. Figure 2 shows an example of temporal H-SSC class successions when restricting to natural evolutions. According to the H-SSC typology we considered in the current study (Section 2), a recently tilled soil with large clods (class T), evolves progressively into a previously tilled soil with a slightly sealed surface (class TC), then into a structural crust (class STC), before reaching the state of sedimentary crust (class SDC). This evolution is conditioned by rainfall amounts between two successive dates (time ti-1 and time ti).

[Figure 2 about here]

Additionally, farmers' soil management practices can occur and modify natural evolutions. Thus, a mechanical weeding / tillage operation just before $\mathrm{t} 3$ or $\mathrm{t} 4$ on Figure 2 would result in H-SSC class T. Knowledge of temporal evolution of H-SSC may be found in field studies about the monitoring of H-SSC under natural or simulated rainfall (Andrieux et al., 2001; Marques, 2004; 
211 Corbane, 2006; Pare et al., 2011). From this knowledge, H-SSC evolution can be derived for a given

212 surface, to predict the set of possible successors PS(ti) at time ti according to:

213 - the antecedent $\mathrm{H}-\mathrm{SSC}$ class $\mathrm{C}(\mathrm{ti}-1)$ at time ti-1, as obtained from the previous iteration that 214 processed the preceding pair of consecutive H-SSC class maps within the time series (Figure 1),

215 - the rainfall amount $\mathrm{P}_{\mathrm{i}}$ between time ti-1 and time ti, as obtained from ancillary rainfall data such as 216 those provided by usual and easy-to-access meteorological databases, and

217 - the soil management practices between time ti-1 and time ti, which has to be detected by the 218 method we proposed here.

219 We discuss hereafter the distinction between natural and anthropogenic evolution rules.

\section{3.1.1. Natural evolution rules}

The knowledge-based rules are compiled in Table 2 in the case of a natural evolution. This table presents the set of possible natural successors Snat related to each combination of antecedent H-SSC class $\mathrm{C}(\mathrm{ti}-1)$ and rainfall amount $\mathrm{P}_{\mathrm{i}}$. The natural successors for T, TC, STC and SDC are established according to the evolution scenario for the vineyard soil structure displayed in Figure 2, provided the initial conditions resulted from tillage (class T). These natural successors correspond to different stages in relation to reconsolidation by raindrop impact and redistribution of soil particles by splash and flow (Robinson and Phillips, 2001).

[Table 2 about here]

Precipitations on STC can induce grass growing, and thus the evolving of STC into GC. Although this evolution is also possible for SDC, it has not been observed on the field and it is therefore disregarded. LC class can evolve into STC or SDC since heavy precipitations can induce litter removal (leach effect) and upslope to downslope transport. The threshold values on rainfall amount are setup according to Andrieux et al. (2001) and Léonard and Andrieux (1998). 
Once conducted, a soil management practice induces specific anthropogenic evolutions that must be considered. A mechanical weeding induces all H-SSC classes evolve into class T, whereas a chemical weeding is usually applied on class GC and can result either in STC or LC, since it induces grass cover death. Table 3 summarizes the possible successors following a soil management practice.

[Table 3 about here]

An example of final set of possible anthropogenic successors Sant induced by a soil management practice is represented in Table 4 for antecedent H-SSC classes of structural crust (STC) and sedimentary crust (SDC). For the STC instance, a mechanical weeding on STC can result in T, TC or STC according to rainfall amount. Similarly, STC can evolve into GC and then, following a chemical weeding, evolve into LC. In its turn, LC evolves into STC or SDC according to rainfall amount (leach effect). For the SDC instance, the chemical weeding is not considered since the change of SDC into GC has not been observed in the field (see natural evolutions in Section 3.1.1).

[Table 4 about here]

Given the number of possible successors for a unique antecedent H-SSC class, expert knowledge is finally used to define the most probable successor, in accordance with field observations 
(Leonard and Andrieux, 1998, Andrieux et al., 2001, Corbane et al., 2008a). For instance, based on the example given in table 4 , following a mechanical weeding and rainfall amount of $30 \mathrm{~mm}$, the most probable successor for STC is T.

\subsection{Rule-based decision system for incorporating expert knowledge}

\subsubsection{Detection of dominant evolution process at the field extent}

The evolution rules outlined in the previous section are applied on each $\mathrm{H}-\mathrm{SSC}$ class $\mathrm{C}(\mathrm{ti}-1)$ at time ti1, to define the set PS(ti) of possible H-SSC successors at time ti, where the possible successors are natural (Snat in Table 2) or anthropogenic (Sant in Table 4). Next, a comparative analysis is conducted between the set of possible successors PS(ti) and the class Cmono(ti) obtained from the monotemporal classification. The comparative analysis consists of checking the presence of Cmono(ti) within the set of possible successors PS(ti), to next identify an evolution scenario among six possible cases of evolutions: natural evolution, mechanical weeding, chemical weeding, combined natural evolution and mechanical weeding, combined natural evolution and chemical weeding, inconsistency (Table 5).

[Table 5 about here]

The occurrences of the six cases are counted at the field extent. For any field, three surface percentages are calculated, in relation to the H-SSC classes that are the most likely to be observed:

- percentage of Sant-MW as the total surface belonging to cases 2 or 4 (mechanical weeding) divided by the field surface;

- percentage of Sant-CW as the total surface belonging to cases 3 or 5 (chemical weeding) divided by the field surface;

- percentage of Snat as the total surface belonging to cases 1 or 4 or 5 (natural evolution) divided by the field surface. 
294 The highest percentage value (\%max) indicates the dominant evolution at the field extent. However, if

\%max is lower than a threshold value, i.e., $70 \%$, the system interrupts and indicates an inconsistency. Finally, the identification of the dominant evolution permits the detection of the soil management practice among mechanical and chemical weeding, when occurring.

\subsubsection{Correction of H-SSC class}

The final stage consists in replacing Cmono(ti) by one element within the set of possible successors PS(ti), when Cmono(ti) is inconsistent with the dominant evolution process at the field extent. In this case Cmono(ti) is replaced by the most probable H-SSC class within PS(ti), as identified from expert knowledge (Section 3.1.2) and given the dominant evolution detected at the field extent. Thus, the rule-based decision system assigns a unique H-SSC class to each pixel or image-object.

\section{CASE STUDY AND IMPLEMENTATION}

This section reports all the materials involved in the implementation and assessment of the proposed multitemporal classification. We present the study area, the in-situ observations of H-SSC classes to be used for validation, the time series of H-SSC class maps obtained from a monotemporal classification of aerial photos, as well as the dataset of rainfall and soil management practices. Finally are presented the implementation and the assessment of the multitemporal classification.

\subsection{Study Area}

The experiment was carried out within a vineyard site at Puisserguier $\left(43^{\circ} 22^{\prime} \mathrm{N}-3^{\circ} 2^{\prime} \mathrm{E}\right)$, located in Languedoc-Roussillon which is a Southern France region of wine production. The climate is Mediterranean sub humid, with a long dry season. The annual rainfall over the last 20 years is about $650 \mathrm{~mm}$. High intensity storms are common in summer. The soil is fairly homogeneous with a sandy loam texture and a dominant brownish yellow colour overlaying sandy clayey molasses. It is neither 
stony nor cracking. During the experiment, the cropping system included bilateral wire trained Syrah vine stocks covering an area of $8000 \mathrm{~m}^{2}$. Spacing between and along rows were 2.5 and $1.0 \mathrm{~m}$.

This experimental site concentrated the main soil management practices for Mediterranean vineyards (Figure 3): bare soil controlled by chemical weeding (Field 1, $2000 \mathrm{~m}^{2}$ ), natural grassing controlled by chemical weeding (Field 2,2100 $\mathrm{m}^{2}$ ), natural grassing controlled by mechanical weeding (Field 3, $2100 \mathrm{~m}^{2}$ ), and sowed grass controlled by mow (Field 4, $1800 \mathrm{~m}^{2}$ ). Among the three different soil management practiced that were encountered on this site (i.e., chemical weeding, mechanical weeding, mow), chemical and mechanical weeding only had a direct impact on H-SSC evolution.

[Figure 3 about here] covered between 1 and $2 \%$ of the whole study area. This set of ground truth data was randomly split in two equal parts devoted to training classification and to assessing classification accuracy.

\subsection{Ground-truthing of H-SSC classes for classification training and validation}

A set of ground truth data was acquired on each date included in the time series of H-SSC class maps, where each date corresponded to an acquisition of remote sensing data (Section 4.3.1). The ground truth data were collected according to a sampling strategy which accounted for the geometrical features of the study site (Corbane et al., 2008a; b). Each of the four fields was sampled by setting around 25 transects with $1.25 \mathrm{~m}$ lengths. Each transects included 25 visual observations of SSC attributes with a $5 \mathrm{~cm}$ step, and was assigned to an H-SSC class according to (i) the fraction cover of each SSC attribute observed within the transect and (ii) the association rules presented in Table 1.

The resulting data set included, for each day of remote sensing data acquisition, about 100 transects equally distributed over the four fields, where each transect corresponded to a unique H-SSC class. Each daily set of about 100 transects with $1 \mathrm{~m}^{2}$ sizes provided a ground truth database that 


\subsection{H-SSC maps derived from a monotemporal classification of aerial photos}

\subsubsection{Airborne images}

A series of airborne images was acquired around solar noon using a remotely controlled Unmanned Airborne Vehicle (UAV) called Pixy® (Asseline et al., 1999). The images were collected on five days in 2004 that corresponded to dry soil conditions (January 04, March 27, May 18, June 15 and July 23). The monthly frequency of photo collection was supposed to capture the temporal dynamics of H-SSC. The UAV flew at an altitude of $150 \mathrm{~m}$, yielding a $0.10 \mathrm{~m}$ spatial resolution. The digital camera was a Minolta DiMAGE 7Hi, featuring a 2/3 in. type CCD sensor with five megapixels. The airborne nadir viewing images were collected using filters centred on 450 (blue), 550 (green) and 650 (red) nm. Reflectance over these three filters were supposed to provide sufficient information for the mapping of H-SSC classes (Corbane et al., 2008b), whereas using an aerial camera with few spectral bands was attractive for operational hydrology at the watershed extent.

Performing H-SSC classification at several dates required normalizing the images collected at different dates. The pre-processing of the raw airborne images included geometric and radiometric corrections, and was completed by spatial and radiometric filtering (Corbane et al. 2008b). Geometric corrections aimed to remove distortions from the camera lens, the camera tilt and the topography effects. Radiometric corrections were twofold. Date-to-date changes in sun illumination were corrected using the method from Richter and Schlaepfer (2002). Date-to-date changes in instrumental response were corrected using daily linear regressions based on invariants. Finally, vine canopy and shadow were removed using a radiometric thresholding on red reflectance (Wassenaar et al., 2005).

\subsubsection{Monotemporal classification method}

376 When selecting the monotemporal classification to be used for deriving time series of H-SSC class 377 maps from aerial photos, two approaches devoted to hydrological SSC could be foreseen, as listed in 
378 the introduction. We selected the method proposed by Corbane et al. (2008b). First, it allowed a better 2379 discrimination of some H-SSC classes as compared to that of Wassenaar et al. (2005). Second, it was 380 already tested on the considered study area. We give here an overview of the monotemporal 381 classification. Method rationales, implementations and performance analysis are discussed in Corbane 382 et al. (2008b), who also addressed the relevance of the underlying assumptions.

\subsubsection{Time series of H-SSC class maps}

[Figure 4 about here]

SSC attributes are assigned at the fine spatial scale by using a nearest neighbour classifier in an object-oriented framework along with preselected training sets, which relies on both spectral and spatial behaviours. Assigning objects at the coarser scale to H-SSC classes relies on (i) the imageobjects identified from the segmentation at both scales, and (ii) the spatial relations between the two scales within the image-objects' hierarchy. The spatial relations are based on a set of decision rules that follow those designed for characterizing ground-based estimates of H-SSC classes (Table 1).

The time series of H-SSC class maps was obtained by implementing the monotemporal classification described in Section 4.3.2 over the data set of aerial photos described in Section 4.3.1. The classification training was conducted using half of the ground-truth observations described in Section 

14

4.2. A portion of the obtained time series is displayed in Figure 5. Significant heterogeneities were observed, in time between the five dates and in space between the four fields.

[Figure 5 about here]

Accuracy assessment was performed by Corbane et al. (2008b) using the other half of the ground-truth observations along with confusion matrices. The best classification accuracy was obtained on January image (Overall accuracy $=0.86$ ). For the other dates, classification accuracies decreased: 0.80 in March, 0.84 in May, 0.69 in June and 0.63 in July.

\subsection{Calendar on rainfall data and agricultural practices}

The chronological diagram presented in Figure 6 displays the dates of image acquisitions in addition to the cumulative rainfall. It also includes the calendar of soil management practices throughout the period of experiment, derived from farmer interviews. The soil management practices were significantly different from one field to another. With regards to the H-SSC temporal dynamics induced by rainfall and soil management practices, the monthly time scale was considered as relevant for monitoring H-SSC temporal evolution from aerial photos. This calendar was used for validating the soil management practices detected with the multitemporal classification.

[Figure 6 about here] 


\subsection{Implementation and assessment of the proposed multitemporal classification}

The multitemporal classification was applied on the time series of H-SSC maps derived from the monotemporal classification of monthly aerial photos (Section 4.3). It was initialized with the first map obtained from the January 2004 flight (classification accuracy of 0.86). It was then tested on the four images of March, May, June and July 2004 acquired over the four fields of the vineyard site.

The performances of the multitemporal classification were assessed in the same way as were those of the monotemporal classification (Section 4.3.3), such as the comparison between both classifications was possible. Accuracies were assessed using half of the ground-based dataset, i.e. the part that was not used for training the monotemporal classification (Section 4.2 and 4.3.3). The pairwise test statistic based on the Kappa coefficients was used to evaluate the significance of differences between the two classification approaches (represented by their respective confusion matrices), as recommended by Cohen (1960).

\section{RESULTS AND DISCUSSION}

We report here the results obtained when analysing the performances of the multitemporal classification. First, we analyse the potential of the multitemporal approach to detect the considered soil management practices (i.e., mechanical and chemical weeding). Next, we compare the performances of the monotemporal and multitemporal classifications, for both each of the four fields and each of the six H-SSC classes. Finally, we discuss the implications of the proposed approach.

\subsection{Detection of soil management practices}

Table 6 represents the calculated surface percentages that were assigned to natural evolution (\%nat), anthropogenic mechanical weeding (\%antMW) and anthropogenic chemical weeding (\%antCW), for each date between March and July 2004 on the four fields. For each date, the maximum percentage 
461 (\%)

[Table 6 about here]

\begin{abstract}
Knowledge soil management practice calendar (Figure 6) allowed verifying the results obtained with the multitemporal classification. The later correctly identified the two mechanical weeding interventions on Field 3, the first one around mid-May and the second one around mid-June (\%antMW $=87$ and 72, respectively). In July, a mechanical weeding was also detected on Field 3 $(\%$ antMW $=92)$ which actually corresponded to the former soil management practice applied around mid-June over this field. The results of the multitemporal classification also indicated that a chemical weeding had been applied on Field 2 in May and July (\%antCW $=74$ and 80, respectively).
\end{abstract}

Comparing to the actual calendar of soil management practices displayed by Figure 6, the detection of chemical weeding was not straightforward. On the one hand, the first intervention around the end of March was detected lately on the image acquired in May. On the other hand, the second and the third interventions applied around the end of June and at the beginning of July, respectively, were successfully identified on the image acquired in July. The differences in the detection timing for mechanical and chemical weeding could be explained by the delay in chemical weeding effect that did not appear immediately after the herbicide application, as compared to the effect of mechanical weeding which was observable right after the passage of the spring-tine rotovator.

\title{
5.2 Evaluation of classification improvement
}

485 We next compared the performances of the monotemporal and multitemporal classifications. Figure 7 486 displays the H-SSC class maps obtained with both classifications in May 2004. For the four dates, 487 Table 7 describes the results of classification assessments obtained on individual fields, and the overall 488 accuracy calculated over the whole vineyard site. 
[Figure 7 about here]

[Table 7 about here]

494 The absolute values of the test $Z$ statistic were larger than the critical value of 1.96 , which 495 suggested that all the classification results obtained by the multitemporal approach were significantly 496 better than those obtained by the monotemporal classification, at a 95\% confidence level. The 497 multitemporal classification outperformed the monotemporal classification for the whole dataset. The 498 higher performance achieved with the multitemporal classification was obtained on Field 2 for the 499 image acquired in March with an overall accuracy of 0.98. On the other hand, the lowest improvement 500 achieved with the multitemporal classification was obtained for the image acquired in May (0.84 501 overall accuracy for monotemporal versus 0.89 overall accuracy for multitemporal). This might be 502 attributed to the relatively good level of accuracy already reached by the monotemporal approach.

Another evaluation of improvements in classification performances is proposed in Figure 8, where relative values are reported for each H-SSC class. As depicted in this graph, a significant improvement in the identification of class SDC was observed on Field 1 (relative improvement about $39 \%$ in March, $17 \%$ in May and 48\% in June) and on Field 2 (21\% in June). An important increase in accuracy was also observed for class STC in March (relative improvement about 35\% on Field 2; 37\% on Field 3 and $20 \%$ on Field 4). Similarly, the identification of classes GC, LC and TC from the multitemporal classification over-performed that from the monotemporal classification, mainly in June for classes GC (31\% on Field 4) and LC (37\% on Field 1) and in July for class TC (18\% on Field 3). On the other hand, accuracy result of class $\mathrm{T}$ did not vary as much with the multitemporal classification, because this class was already well detected by the monotemporal classification.

[Figure 8 about here] 
2518 showed that using expert knowledge about H-SSC evolutions satisfactorily improved the identification 519 of misclassified H-SSC classes, mainly classes related to crusting processes (SDC and STC). The 520 improvement was manifest (i) in the overall accuracy assessments per field and for the whole vineyard 521 site and (ii) in the identification of individual H-SSC classes.

\subsection{Advantages and limits of the knowledge-based multitemporal classification}

The method based on expert knowledge on possible H-SSC evolutions is worthwhile for detecting both natural and human induced evolutions, such as the effects of chemical and mechanical weeding on H-SSC dynamics. Since mechanical weeding has an instantaneous effect on the evolution of HSSC, it was correctly identified using the multitemporal reasoning. On the other hand, the delayed effects of chemical weeding induced the date of image acquisition becomes very critical for the detection of this specific practice. This explains the ineptitude of the system in identifying the first chemical weeding on Field 2 in March when the image was acquired three days after the application of glyphosate. Yet, the first chemical weeding was identified lately on the image acquired in May. Thus, the knowledge-based multitemporal classification has potential in detecting soil management practices, provided the remotely sensed observations are collected with an adequate frequency in relation to these practices.

This case study demonstrates that the timing of image acquisitions is not that critical for an adequate detection of the dominant evolution process. However, with respect to the natural evolution of H-SSC in relation to the rainfall amount and to the frequency of soil management practices, an acceptable time interval for multitemporal monitoring would be an aerial photograph acquisition per month. On the other hand, the aerial photographs had a spatial resolution of $0.1 \mathrm{~m}$, which raises the question of portability to spaceborne remote sensing systems. Indeed, the best spatial resolution for multispectral sensor is 1.84 metres with WorldView-2, to be compared with the $2.5 \mathrm{~m}$ inter-row spacing of the vineyard we studied here. 
The quantitative evaluation of classification improvements indicated the superiority of the results produced when employing expert knowledge, as compared to the outcomes of the monotemporal classification. The knowledge-based multitemporal classification presented in this paper has strengths in straightforwardness and simplicity. The ancillary data required as inputs, i.e., amount of rainfall and expert knowledge, can be easily acquired at a relatively low cost. This is consistent with the consideration of UAVs carrying cameras with few spectral bands, thus constituting an attractive tool for operational hydrology at the watershed extent.

A particular attention must be given to the geometric accuracy and the precision in imageoverlay database, which requires an accurate georeferencing procedure. In the multidate approach, uncertainty is mostly related to the superimposition process. For instance, in the case of vineyards, a vine and shadow mask was applied on the images, because we were interested in the sunlit soil surfaces only. The size of the mask generally increases from January to July with the increase of vineyard canopy density, thus always ensuring the existence of an antecedent $\mathrm{H}-\mathrm{SSC} \mathrm{C}(\mathrm{ti}-1)$ for all image-objects. The problem would arise when the size of the mask decreases during the senescence season, although remotely sensed acquisitions around solar noon mitigate shadow effects. In this case, we advocate applying the monotemporal classification on this particular period in order to reset the multitemporal classification schema and to avoid the difficulties induced by the absence of antecedent 564 H-SSC class, where the latter is an essential input for the rule-based decision system.

An important critical point is linked to the choice of a reliable map for initializing the multitemporal classification. Ideally, an exhaustive thematic map on H-SSC could be used for initialization. Practically, it is impossible to obtain such information, and we initialised the multitemporal approach with the H-SSC class maps obtained from the monotemporal classification on the first date, given the accuracy was larger than 0.8 . However, because the quality of the results is subject to progressive deviation, the error propagation has to be analysed in future works, such as it is possible evaluating its impact on the outcomes of the multitemporal classification. 
In this case study, the H-SSC evolution rules that were implemented into the multitemporal classification framework were obtained from previous and exploratory field studies. Field research on H-SSC evolutions in relation to rainfall intensity is currently being conducted (Pare et al., 2011). The expert knowledge could then be complemented by obtaining quantitative information on evolutions of H-SSC classes, from the typology of Andrieux et al. (2001), and by implementing this information into the multitemporal classification system. Refining the expert knowledge would obviously improve the classification performances, adding more interest to the approach proposed in this paper. Finally, progressing towards genericity requires first addressing other agricultural practices.

\section{Concluding remarks}

Some directions for future work would consist of (i) refining the expert knowledge by acquiring new information on possible evolution of all H-SSC classes and (ii) analysing error propagation. Further investigations are also required (i) to apply this approach on other sequences of H-SSC maps derived from any monotemporal classification of H-SSC and (ii) to monitor H-SSC over larger areas and under different soil management and cultivation conditions. Finally, the current paper investigated one way of improvement for the monotemporal classification of H-SSC, by incorporating a priori information about H-SSC evolution. Using richer spectral information from spectroscopy and hyperspectral imagery is the other potential direction to be deepened for improvement, since it is a promising alternative for characterizing physicochemical properties of soil surface, including crusts.

\section{Acknowledgments}

We express our profound gratitude to Mr. Jean Asseline for his assistance in collecting the aerial photos. We also thank LISAH (Laboratoire d'étude des Interactions Sol - Agrosystème Hydrosystème) technicians for their participation in the field campaigns. This research is supported by 
"XIIe Contrat de Plan Etat Région-LR" and a PhD studentship granted to C. Corbane by IRD (Institut 2601 de Recherche pour le Développement).

\section{References}

Andrieux, P., Hatier, A., Asseline, J., de Noni, G., Voltz, M., 2001. Predicting infiltration rates by classifying soil surface features in a Mediterranean wine-growing area. Oral communication. International Symposium "The Significance of Soil Surface Characteristics in Soil Erosion. COST 623 "Soil Erosion and Global Change" workshop, Strasbourg.

Asseline, J., de Noni, G., Chaume, R., 1999. Note on the design and use of a slow drone for remote sensing. Photo Interprétation 37, 3 - 9 (in French).

Auzet, V., Poesen, J., Valentin, C., 2001. Soil patterns as a key controlling factor of water erosion. Catena 46, 2-3.

Baghdadi, N., King, C., Bourguignon, A., Remond, A., 2002. Potential of ERS and Radarsat data for surface roughness monitoring over bare agricultural fields: Application to catchments in Northern France. International Journal of Remote Sensing 23, 3427-3442.

Bartholomeus, H., Epema, G.F., Schaepman, M., 2007. Determining iron content in Mediterranean soils in partly vegetated areas, using spectral reflectance and imaging spectroscopy. International Journal of Applied Earth Observation and Geoinformation 9, 194-203.

Bartholomeus, H., Kooistra, L. Stevens, A., Van Leeuwen, M., Van Wesemael, B., Ben-Dor, E., Tychon, B. 2011. Soil organic matter mapping of partially vegetated agricultural fields with imaging spectroscopy. International Journal of Applied Earth Observation and Geoinformation 13, $81-88$

Ben-Dor, E., Patkin, K., Banin A., Karnieli, A., 2002. Mapping of soil properties using DAIS-7915 hyperspectral scanner data - a case study over clayey soils in Israel. International Journal of Remote Sensing 23, 1043-1062. 
626 Ben-Dor, E., Goldlshleger, N., Benyamini, Y., Agassi, M., Blumberg, D.G., 2003. The spectral 627 reflectance properties of soil structural crusts in the $1.2-$ to $2.5-\mu \mathrm{m}$ spectral region. Soil Science 628 Society of America Journal 67, 289-299.

629 Ben-Dor, E., Goldshleger, N., Braun, O., Kindel, B., Goetz, A.F.H., Bonfil, D., Margalit, N., 630 Benyamini, Y., Karnieli, A., Agassi, M., 2004. Monitoring infiltration rates in semiarid soils using airborne hyperspectral technology. International Journal of Remote Sensing 25 (13), 2607-2624.

Boiffin, J., Monnier, G., 1986. Infiltration rate as affected by soil surface crusting caused by rainfall. In Callebaut et al. eds., Assessment of soil surface sealing and crusting. Ghent, Belgium: Flanders Research Centre for Soil Erosion and Soil Conservation, 210-217.

Cerdan, O., Souchère, V., Lecomte, V., Couturier, A., L. Bissonnais, Y., 2001. Incorporating soil surface crusting processes in an expert-based runoff and erosion model: STREAM (Sealing and Transfer by Runoff and Erosion related to Agricultural Management). Catena 46, 189-205.

Cohen, J. 1960. A coefficient of agreement for nominal scale. Educational and Psychological Measurement 20:37-40.

Corbane, C. 2006. Recognition of soil surface characteristics within Mediterranean agricultural areas by using high spatial resolution optical remote sensing, Montpellier II University, Montpellier (in French).

Corbane, C., Andrieux, P., Voltz, M., Chadoeuf, J., Albergel, J., R. Masson, J.M., Zante, P., 2008a. Assessing the variability of soil surface characteristics in row-cropped fields: the case of Mediterranean vineyards in Southern France. Catena 72, 79-90.

Corbane, C., Raclot, D., Jacob, F., Albergel, J., Andrieux, P., 2008b. Remote sensing of soil surface characteristics from a multiscale classification approach. Catena 75, 308-318.

Descroix, L., Gonzalez Barrios, J.L., Vandervaere, J.P., Viramontes, D., Bollery, A., 2002. An experimental analysis of hydrodynamic behaviour on soils and hillslopes in a subtropical mountainous environment (Western Sierra Madre, Mexico). Journal of Hydrology 266, 1-14.

Descroix, L., Viramontes, D., Vauclin, M., Gonzalez Barrios, J.L., Esteves, M., 2001. Influence of soil surface features and vegetation on runoff and erosion in the Western Sierra Madre / Durango, Northwest Mexico. Catena 43:115-135. 
654 Dunne, T., Dietrich, W. E., 1980. Experimental study of Horton overland flow on tropical hillslopes: 655 II. Hydraulic characteristics and hillslope hydrographs: Zeitschrift für Geomorphologie, Suppl. Bd. $656 \quad 35$, p. $60-80$.

657 Goldshleger, N., Ben-Dor, E., Benyamini, Y., Agassi, M., Blumberg, D.G., 2001. Characterization of 658 soil's structural crust by spectral reflectance in the SWIR region $(1.5-2.5 \mu \mathrm{m})$. Terra Nova $13(1)$,

Goldshleger, N., Ben-Dor, E., Benyamini, Y., Blumberg, D.G., Agassi, M., 2002. Spectral properties and hydraulic conductance of soil crusts formed by raindrop impact. International Journal of Remote Sensing 23, 3909-3920.

Goldshleger, N., Ben-Dor, E., Benyamini, Y., Agassi, M., 2004. Soil reflectance as a tool for assessing physical crust arrangement of four typical soils in Israel. Soil Science 169 (10), 677-687.

Janssen, L.F., Middelkoop, H., 1992. Knowledge-Based Crop Classification of a Landsat Thematic Mapper Image. International Journal of Remote Sensing 13, 2827-2837.

Jetten, V., Boiffin, J., de Roo, A., 1996. Defining monitoring strategies for runoff and erosion studies in agricultural catchments: a simulation approach. European Journal of Soil Science 47, 579-592.

de Jong S.M., Addink, E.A., van Beek, L.P.H., Duijsing, D., 2011. Physical Characterization and Spectral Response of Mediterranean Soil Surface Crusts. Catena 86, 24-35.

Lagacherie, P., Baret, F., Feret, J.B., Madeira Netto, J., Robbez-Masson, J.M., 2008. Estimation of soil clay and calcium carbonate using laboratory, field and airborne hyperspectral measurements. Remote Sensing of Environment 112, 825-835.

Largouët, C., Cordier, M.O., 2001. Improving the land cover classification using domain knowledge. AI Communication 14 (1), 35-43.

Lelong, F., Roose, E., Darthout, R., Trevisan, D., 1993. Susceptibilité au ruissellement et à l'érosion en nappe de divers types texturaux de sols cultivés ou non cultivés du territoire français. Expérimentation au champ sous pluies simulées. Science du Sol, 31, 251-279.

Lennartz, B., Louchart, X., Voltz, M., Andrieux, P., 1997. Diuron and simazine losses to runoff water in Mediterranean vineyards. Journal of Environmental Quality 26, 1493-1502. 
681 Léonard, J., Andrieux, P., 1998. Infiltration characteristics of soils in Mediterranean vineyards in southern France. Catena 32, 209-223.

Liu, G., Xu, M., Ritsema, C., 2003. A study of soil surface characteristics in a small watershed in the hilly, gullied area on the Chinese Loess Plateau. Catena 54, 31-44.

Louchart, X., Voltz, M., Andrieux, P., Moussa, R., 2001. Herbicide transport to surface waters at field and watershed scales in a Mediterranean vineyard area. Journal of Environmental Quality 30, $982-$ 991.

Lucas, R., Rowlands, A., Brown, A., Keyworth, S., Bunting, P., 2007. Rule-based classification of multi-temporal satellite imagery for habitat and agricultural land cover mapping. ISPRS Journal of Photogrammetry and Remote Sensing 62, 165-185.

Marques, I., 2004. Impact of Mediterranean vineyard soil management practices on soil surface characteristics, runoff and erosion. Master of Science dissertation (Lleida University, Spain). UMR LISAH, Montpellier (in French).

Mota, G.L.., Feitosa, R.., Coutinho, H.L.C., Liedtke, C.E., Muller, S., Pakzad, K., Meirelles, M.S.P., 2007. Multitemporal fuzzy classification model based on class transition possibilities. ISPRS Journal of Photogrammetry and Remote Sensing 62, 186-200.

Moussa, R., Voltz, M., Andrieux, P., 2002. Effects of the spatial organization of agricultural management on the hydrological behaviour of a farmed catchment during flood events. Hydrological processes 16, 393-412.

Pare, N., Andrieux, P., Louchart, X., Biarnès, A., Voltz, M., 2011. Predicting the spatiotemporal dynamic of soil surface characteristics after tillage. Soil and Tillage Research 114 (2), 135-145.

Poesen, J., Ingelmo-S.F., Mücher, H., 1990. The hydrological response of soil surfaces to rainfall as affected by cover and position of rock fragments in the top layer. Earth Processes and Landforms, $15,653-671$.

Raclot, D., Colin, F., Puech, C., 2005. Updating land cover classification using a rule-based decision system. International Journal of Remote Sensing 26, 1309-1321. 
Robinson, D.A., Phillips, C.P., 2001. Crust development in relation to vegetation and agricultural 708 3 470 Tillage Research 60, 1-9.

Wang, J., Hsu, A., Shi, J.C., O'neil, P., Engman, T., 1997. Estimating surface soil moisture from SIRC measurements over the Little Washita River watershed. Remote Sensing of Environment 59, 308-320.

Wassenaar, T., Andrieux, P., Baret, F., Robbez-Masson, J.M., 2005. Soil surface infiltration capacity classification based on the bi-directional reflectance distribution function sampled by aerial photographs. The case of vineyards in a Mediterranean area. Catena 62, 94-110.

Weber, B., Olehowski, C., Knerr, T., Hill, J., Deutschewitz, K., Wessels, D.C.J., Eitel, B., Büdel, B., 2008. A new approach for mapping biological soil crusts in semi-desert areas with hyperspectral imagery. Remote Sensing of Environment 112, 2187-2201.

Wiegand, L., Everitt, H., Richardson, J., 1992. Comparison of multispectral video and SPOT/HRV observations for cotton affected by soil salinity. International Journal of Remote Sensing 13, 1511 1525. 


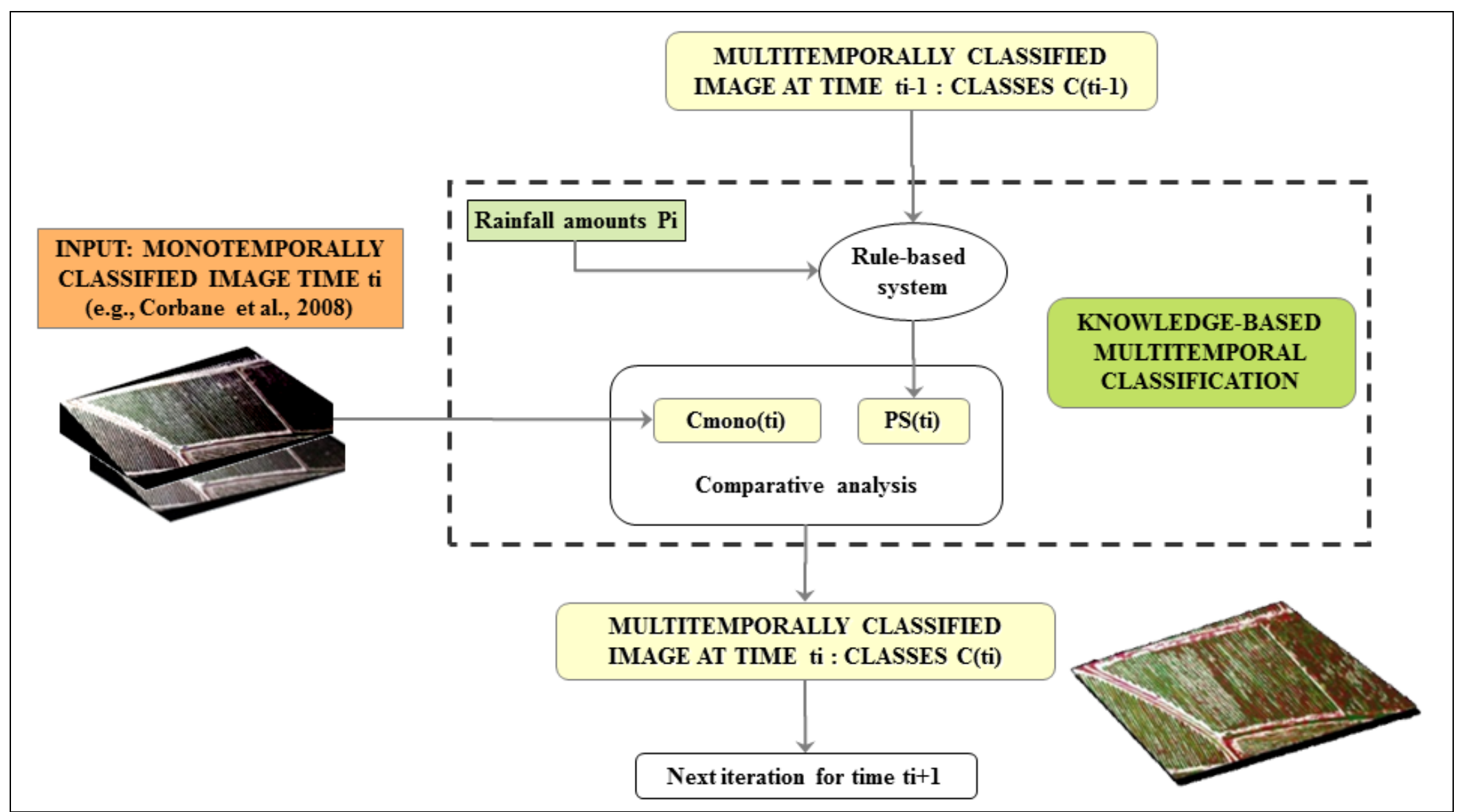

Figure 1: flow-chart of the multitemporal classification at time ti. C(ti-1) is the antecedent H-SSC class obtained from the multitemporal classification at previous time ti-1. "PS(ti)" is the set of Possible Successors at time ti when applying the H-SSC evolution rules to C(ti-1). "Cmono(ti)" is the classification result from the monotemporal method at time ti. Comparative analysis of "Cmono(ti)" and "PS(ti)" provides C(ti) at time ti. The design of the rule-based system for H-SSC evolution is presented in Section 3.1. The comparative analysis between Cmono(ti) and PS(ti) is presented in section 3.2. It includes (i) the detection of the dominant H-SSC evolution at the field scale (Section3.2.1) and (ii) the possible correction of H-SSC assignation when necessary (3.2.2). 
Figure 2: example of a temporal scenario for successive states of soil surface characteristics.

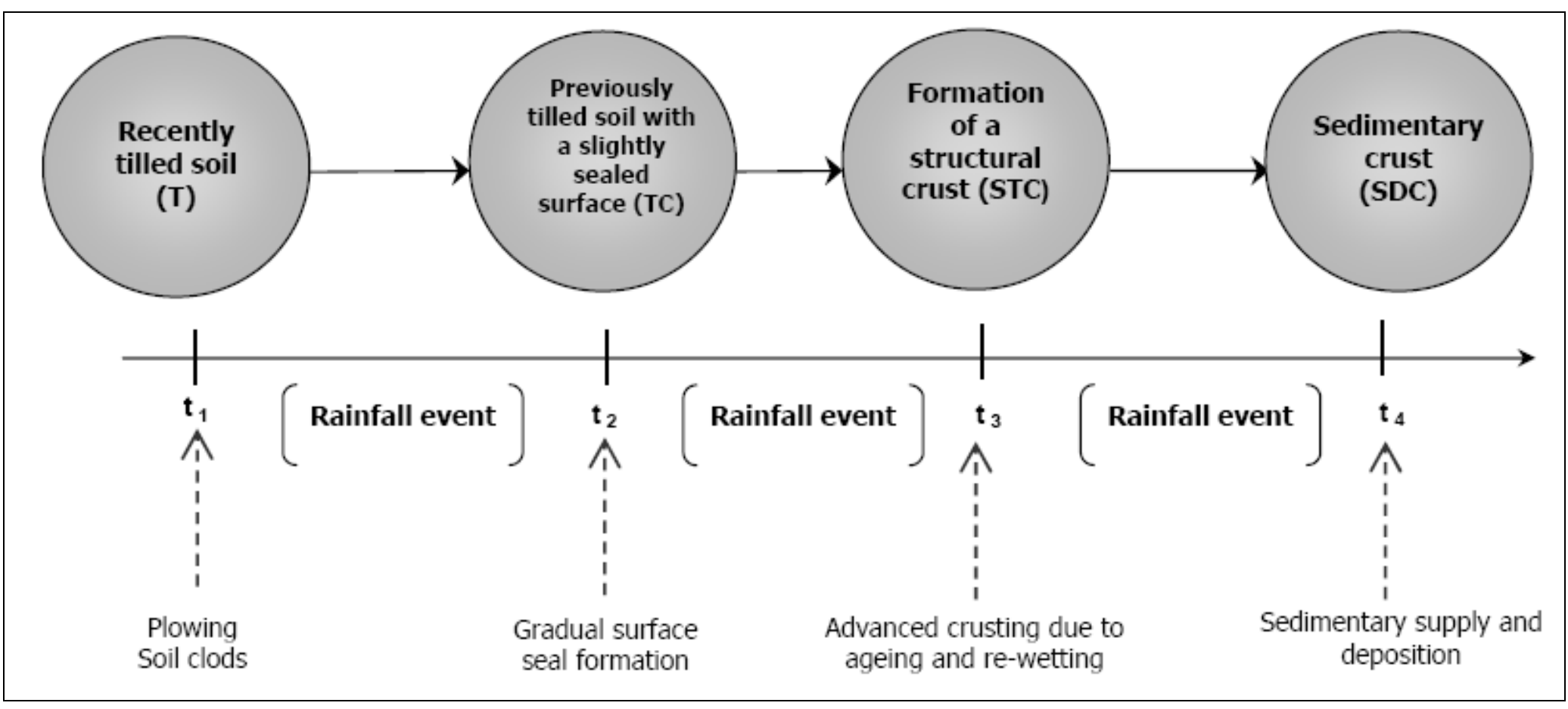




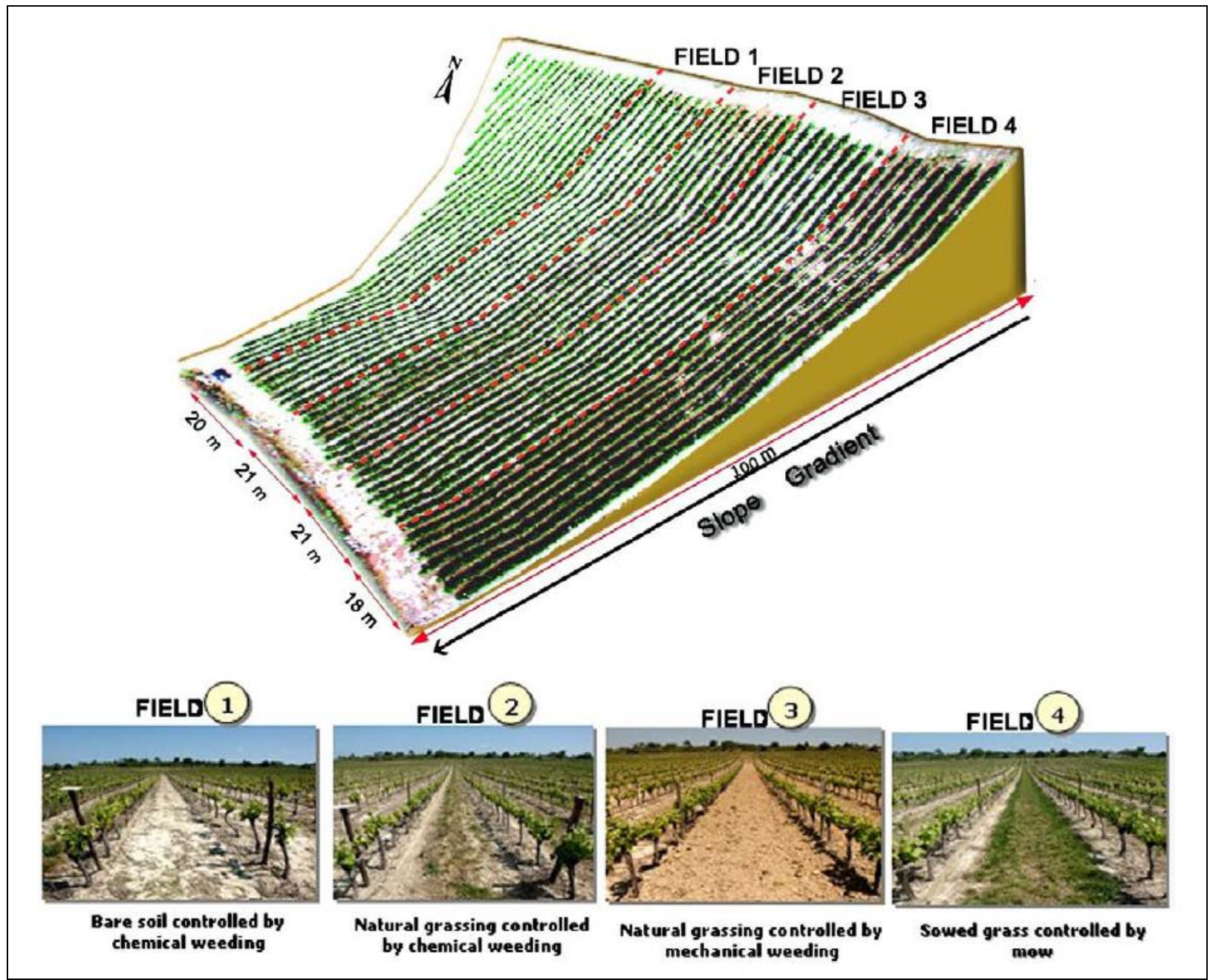

Figure 3: the experimental vineyard site. This site is divided into four fields, each subject to a specific soil management practice. 


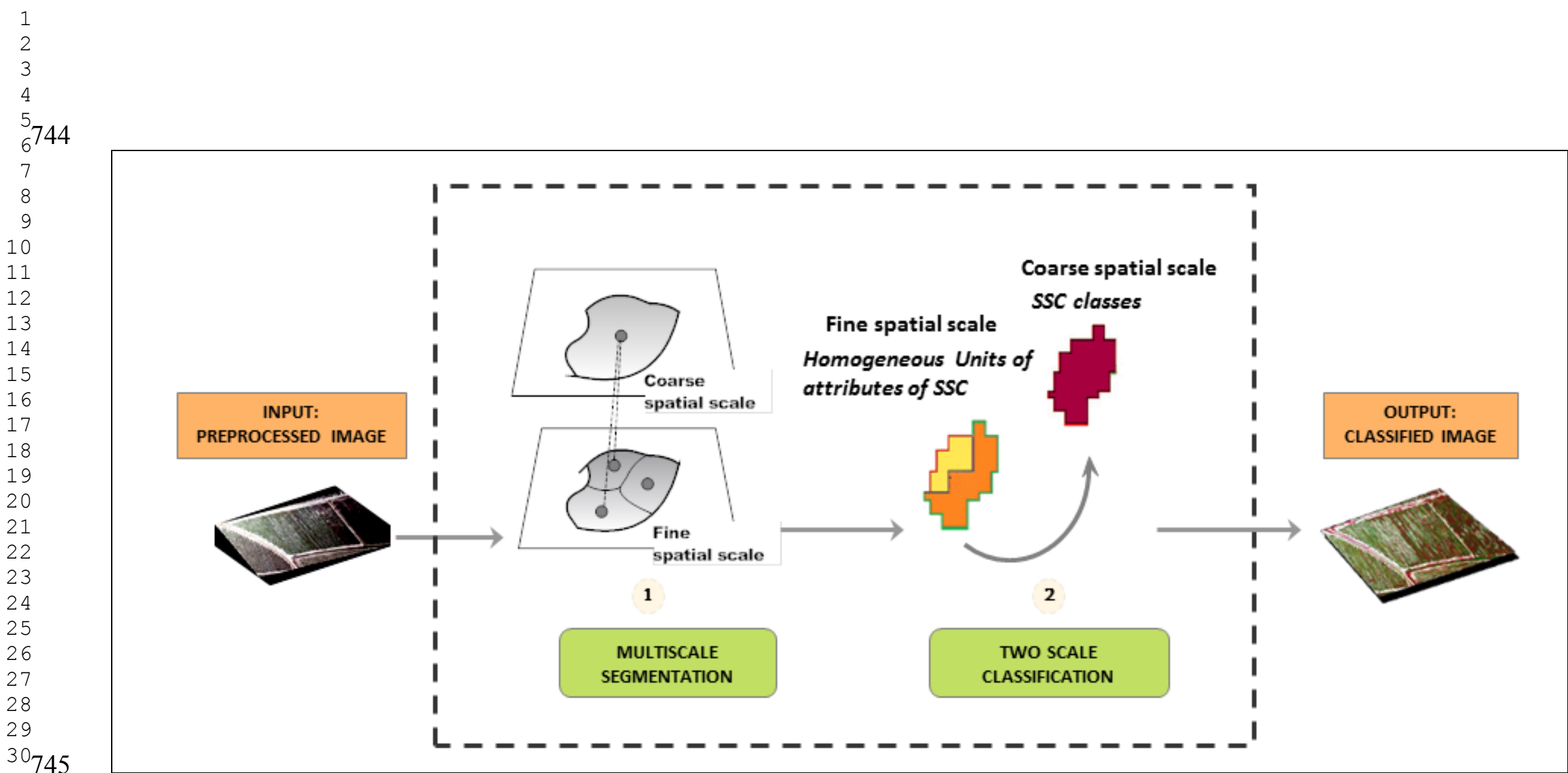

Figure 4: flow-chart of the H-SSC monotemporal classification methodology. From Corbane et al. (2008b). 
MARCH

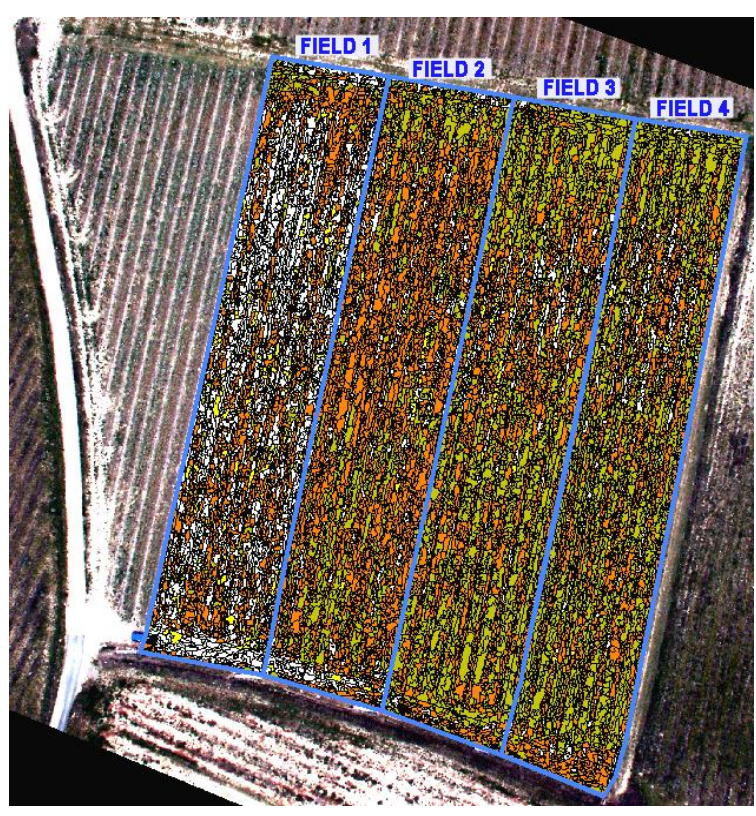

JUNE

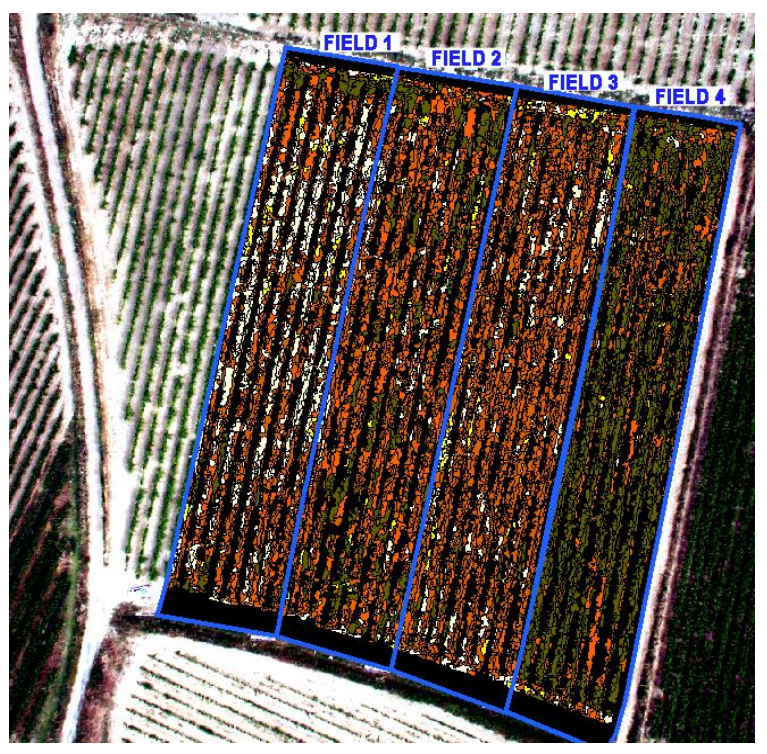

SSC classes

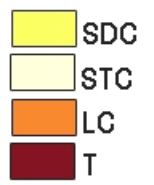

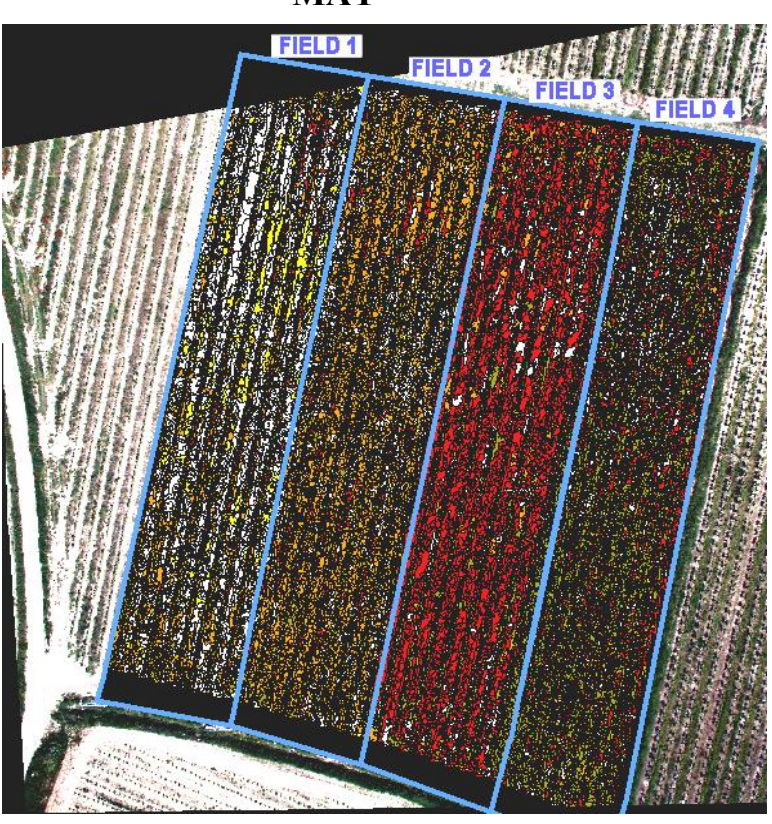

JULY

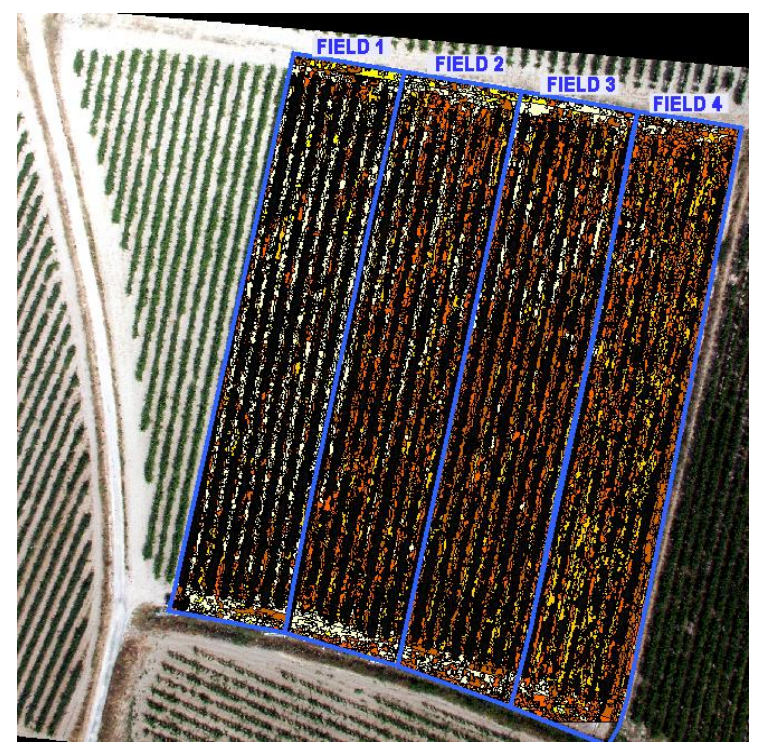

Figure 5: time series of H-SSC class maps obtained when applying the monotemporal classification to the aerial photos monthly collected over the Puisserguier vineyard site. From Corbane et al. (2008b). 


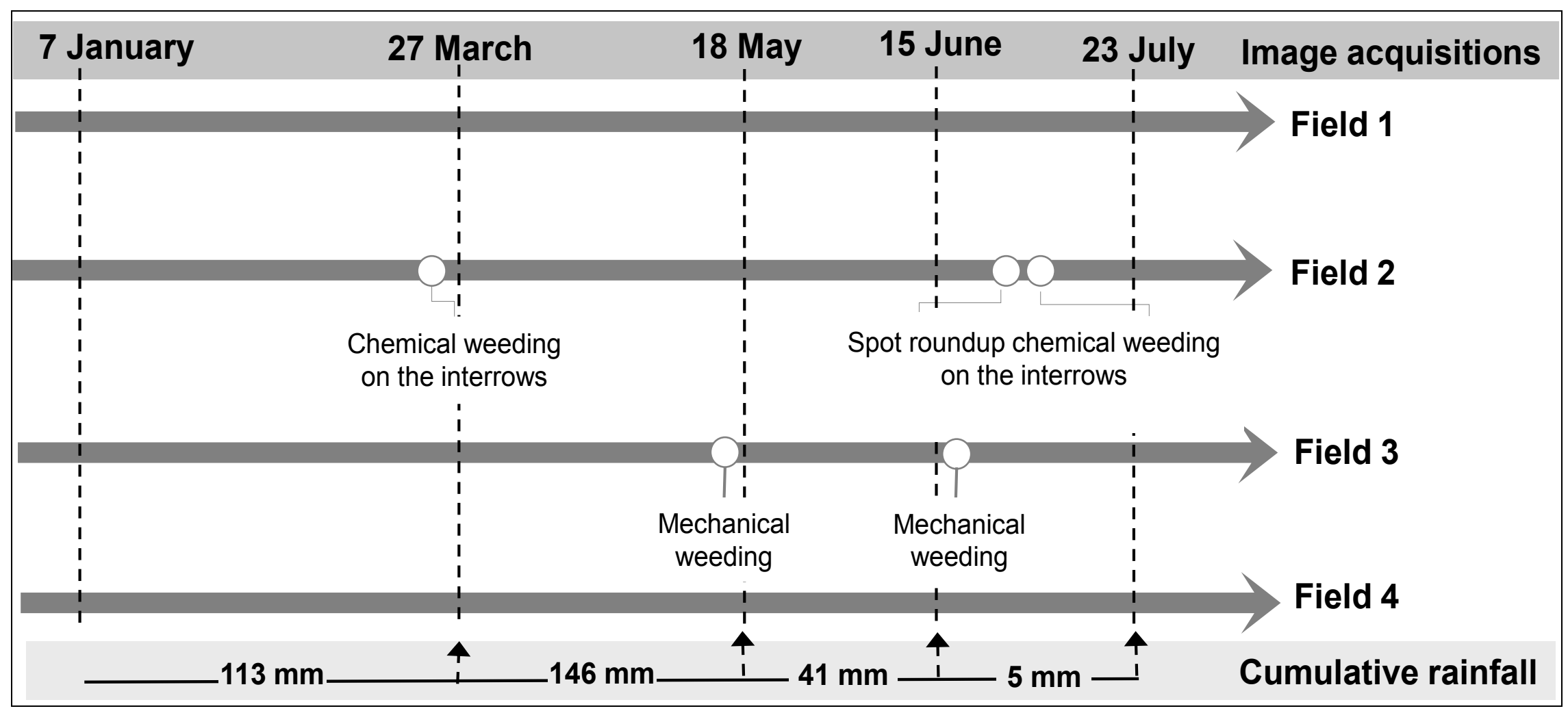

Figure 6: calendar of soil management practices and cumulative rainfall amounts registered between two dates of consecutive image acquisitions. 

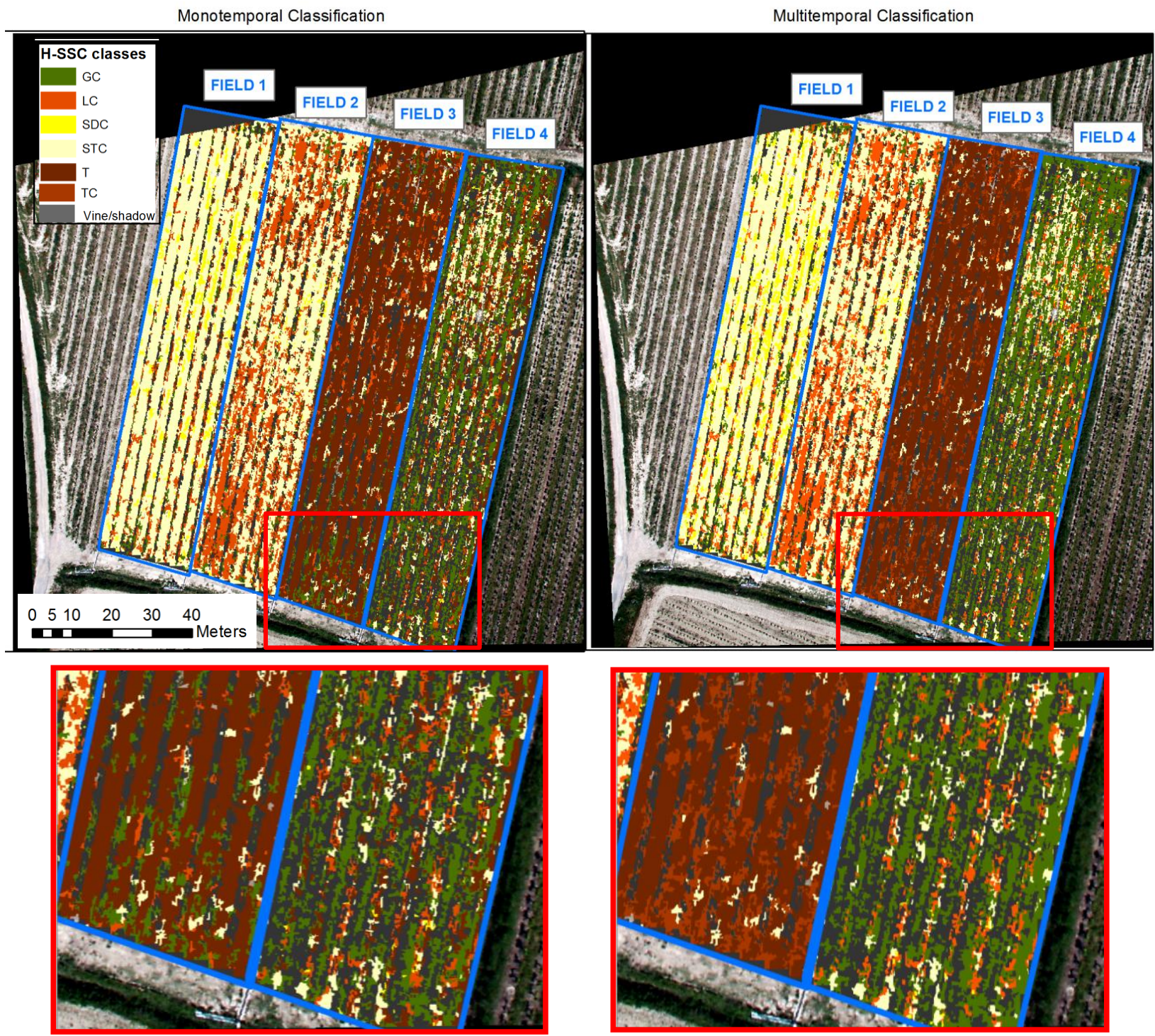

Figure 7: H-SSC class maps obtained with monotemporal (left) and multitemporal (right) classifications for May 18, 2004. Top subplots are H-SSC class maps obtained over the whole study area, where the squares indicate the specific areas that are zoomed in bottom subplots to illustrate changes between monotemporal (left subplots) and multitemporal (right subplots) classifications. 


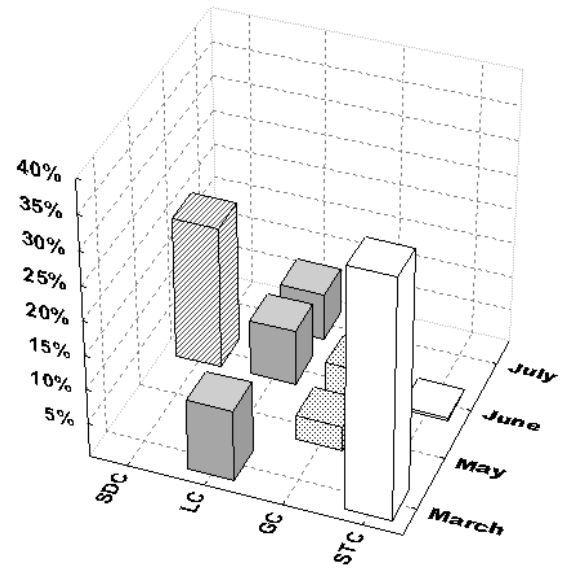

b) Field 2

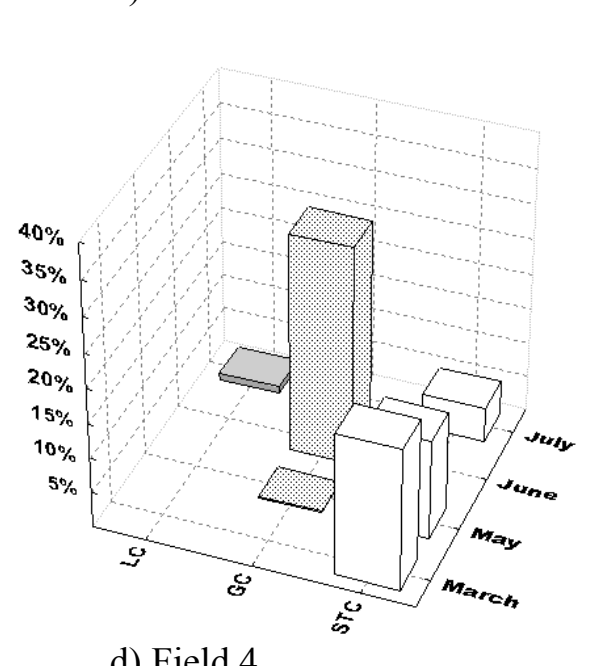

d) Field 4 c) Field 3

Figure 8: comparison of the results of monotemporal and multitemporal classifications by H-SSC class in terms of relative accuracy improvements on Field 1 (5-a), Field 2 (5-b), Field 3 (5-c) and Field 4 (5-d). 


\begin{tabular}{|c|c|c|c|}
\hline & Label & Definition & Mean Infiltration rate \\
\hline \multirow[t]{6}{*}{$\begin{array}{l}\text { H-SSC } \\
\text { classes }\end{array}$} & $\mathrm{T}$ & $\begin{array}{l}\text { The surface is mainly composed of } 5-10 \mathrm{~cm} \\
\text { size clods }\end{array}$ & $31(\mathrm{SD}=4.3 ; \mathrm{N}=5)$ \\
\hline & $\mathrm{TC}$ & $\begin{array}{l}\text { More than } 50 \% \text { of the surface is composed } \\
\text { of clods with a slightly sealed surface }\end{array}$ & $21(\mathrm{SD}=6.5 ; \mathrm{N}=7)$ \\
\hline & $\mathrm{GC}$ & $\begin{array}{l}\text { More than } 50 \% \text { of the surface is composed } \\
\text { of grass AND the rest is predominantly } \\
\text { composed of structural crust }\end{array}$ & $20.3(\mathrm{SD}=10.8 ; \mathrm{N}=9)$ \\
\hline & $\mathrm{LC}$ & $\begin{array}{l}\text { More than } 50 \% \text { of the surface is composed } \\
\text { of litter AND the rest is predominantly } \\
\text { composed of structural crust }\end{array}$ & $18.2(\mathrm{SD}=6.3 ; \mathrm{N}=20)$ \\
\hline & STC & $\begin{array}{l}\text { More than } 50 \% \text { of the surface is composed } \\
\text { of structural crust }\end{array}$ & $10.8(\mathrm{SD}=3.4 ; \mathrm{N}=8)$ \\
\hline & SDC & $\begin{array}{l}\text { More than } 50 \% \text { of the surface is composed } \\
\text { of sedimentary crust }\end{array}$ & $7.6(\mathrm{SD}=2.6 ; \mathrm{N}=19)$ \\
\hline
\end{tabular}

Table 1: the six H-SSC classes we considered in the current study. Each H-SSC class is defined through its constituting SSC attributes. The related infiltration rates measured in situ with a rainfall simulator (Léonard and Andrieux, 1998) are also presented. SD stands for standard deviation and $\mathrm{N}$ for measurement number. 
Antecedent

H-SSC class

Possible Successors Snat

C(ti-1)

\begin{tabular}{cccc}
\hline & \multicolumn{3}{c}{ Rainfall amount $\mathbf{P}_{\mathbf{i}}$} \\
& $\mathbf{[ 0} \mathbf{- 2 0} \mathbf{~ m m}[$ & {$[\mathbf{2 0}-\mathbf{4 0} \mathbf{~ m m}[$} & $\mathbf{2} \mathbf{4 0} \mathbf{~ m m}$ \\
\cline { 2 - 4 } $\mathrm{T}$ & $\mathrm{T}$ & $\mathrm{TC} / \mathrm{STC}$ & $\mathrm{STC} / \mathrm{SDC}$ \\
$\mathrm{TC}$ & $\mathrm{TC}$ & $\mathrm{TC} / \mathrm{STC}$ & $\mathrm{STC} / \mathrm{SDC}$ \\
$\mathrm{STC}$ & $\mathrm{STC} / \mathrm{GC}$ & $\mathrm{STC} / \mathrm{GC}$ & $\mathrm{STC} / \mathrm{SDC} / \mathrm{GC}$ \\
$\mathrm{SDC}$ & $\mathrm{SDC}$ & $\mathrm{SDC}$ & $\mathrm{SDC}$ \\
$\mathrm{GC}$ & $\mathrm{GC}$ & $\mathrm{GC}$ & $\mathrm{GC}$ \\
$\mathrm{LC}$ & $\mathrm{LC}$ & $\mathrm{LC}$ & $\mathrm{LC} / \mathrm{STC} / \mathrm{SDC}$ \\
\hline
\end{tabular}

Table 2: possible H-SSC successors (Snat) related to natural evolutions. 


\begin{tabular}{cc}
$\begin{array}{c}\text { Antecedent H-SSC } \\
\text { class C(ti-1) }\end{array}$ & $\begin{array}{c}\text { Anthropogenic } \\
\text { successors Sant }\end{array}$ \\
\hline T & $\mathbf{T}$ \\
TC & $\mathbf{T}$ \\
STC & $\mathbf{T}$ \\
SDC & $\mathbf{T}$ \\
GC & $\mathbf{T} / S T C / L C$ \\
LC & $\mathbf{T}$ \\
\hline
\end{tabular}

Table 3: possible H-SSC successors related to soil management practices. In bold: possible successors after mechanical weeding. In italic: possible successors after chemical weeding. 
Antecedent

H-SSC class

Possible Successors Sant C(ti-1)

\begin{tabular}{cccc}
\hline & & \multicolumn{2}{c}{ Rainfall amount $\mathbf{P}_{\mathbf{i}}$} \\
& {$[\mathbf{0}-\mathbf{2 0} \mathbf{~ m m}[$} & {$[\mathbf{2 0}-\mathbf{4 0} \mathbf{~ m m}[$} & $\geq \mathbf{4 0} \mathbf{~ m m}$ \\
\cline { 2 - 4 } STC & $\mathbf{T}$ & T/TC/STC & T/TC/STC/SDC/ \\
SDC & $\mathbf{T}$ & T/TC/STC & T/TC/STC \\
\hline
\end{tabular}

Table 4: examples, for antecedent H-SSC classes C(ti-1) STC and SDC, of sets of possible anthropogenic successors Sant related to soil management practices. These H-SSC successors are obtained by considering possible combinations of natural forcing (Table 2) and anthropogenic forcing (Table 3). In bold: possible successor(s) Sant-MW for Mechanical Weeding (MW). In italic: possible successor(s) Sant$\mathrm{CW}$ for Chemical Weeding $(\mathrm{CW})$. 


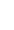

Cmono(ti) versus PS(ti) Corresponding cases

Cmono(ti) $\in \operatorname{Snat} \wedge \notin \operatorname{Sant}-M W \wedge \notin$ Sant-CW $\quad$ Case 1: natural evolution

Cmono(ti) $\notin$ Snat $\wedge \in$ Sant-MW Case 2: mechanical weeding

Cmono(ti) $\notin$ Snat $\wedge \in$ Sant-CW Case 3: chemical weeding

Cmono(ti) $\in$ Snat $\wedge \in$ Sant-MW Case 4: mechanical weeding and natural evolution

Case 5: chemical weeding and natural evolution

Case 6: inconsistency

Table 5: the six possible cases when checking the presence of Cmono(ti) within the set of possible successors PS(ti). Sign $\in$ reads “is an element of", sign $\notin$ reads "is not an element of", sign $\wedge$ reads "and”. 


\begin{tabular}{llllll} 
DATE & Occurrence & Field 1 & Field 2 & Field 3 & Field 4 \\
\hline MARCH & & & & & \\
27/03/2004 & \% nat & $\mathbf{9 2}$ & $\mathbf{7 8}$ & $\mathbf{7 5}$ & $\mathbf{7 2}$ \\
& \% antMW & 40 & 21 & 16 & 15 \\
MAY & \% antCW & 60 & 27 & 30 & 30 \\
18/05/2004 & \% nat & $\mathbf{7 4}$ & 31 & 42 & $\mathbf{7 4}$ \\
& \% antMW & 49 & 28 & $\mathbf{8 7}$ & 26 \\
JUNE & \% antCW & 05 & $\mathbf{7 4}$ & 21 & 23 \\
15/06/2004 & \% nat & $\mathbf{8 9}$ & $\mathbf{8 6}$ & 21 & $\mathbf{7 1}$ \\
& \% antMW & 23 & 19 & $\mathbf{7 3}$ & 14 \\
JULY & $\%$ antCW & 55 & 36 & 30 & 29 \\
23/07/2004 & \% nat & $\mathbf{8 1}$ & 31 & 37 & $\mathbf{8 4}$ \\
& $\%$ antMW & 14 & 19 & $\mathbf{9 2}$ & 16 \\
& \% antCW & 36 & $\mathbf{8 0}$ & 19 & 24 \\
\hline
\end{tabular}

814

815 Table 6: results from calculations of surface percentages of natural evolution (\%nat), anthropogenic 816 mechanical weeding (\%antMW) and anthropogenic chemical weeding (\%antCW) obtained over the four 817 fields for dates between March and July 2004. Bold numbers correspond to maximum value for a given 818 field and a given date. 


\begin{tabular}{lcccccccc} 
& \multicolumn{2}{c}{ MARCH } & \multicolumn{2}{c}{ MAY } & \multicolumn{2}{c}{ JUNE } & \multicolumn{2}{c}{ JULY } \\
\hline & $\begin{array}{c}\text { Mono- } \\
\text { temporal }\end{array}$ & $\begin{array}{c}\text { Multi- } \\
\text { temporal }\end{array}$ & $\begin{array}{c}\text { Mono- } \\
\text { temporal }\end{array}$ & $\begin{array}{c}\text { Multi- } \\
\text { temporal }\end{array}$ & $\begin{array}{c}\text { Mono- } \\
\text { temporal }\end{array}$ & $\begin{array}{c}\text { Multi- } \\
\text { temporal }\end{array}$ & $\begin{array}{c}\text { Mono- } \\
\text { temporal }\end{array}$ & $\begin{array}{c}\text { Multi- } \\
\text { temporal }\end{array}$ \\
\hline Field 1 & 0.75 & 0.87 & 0.76 & 0.87 & 0.70 & 0.86 & 0.78 & 0.81 \\
Field 2 & 0.90 & 0.98 & 0.92 & 0.96 & 0.86 & 0.89 & 0.76 & 0.79 \\
Field 3 & 0.60 & 0.68 & 0.89 & 0.92 & 0.50 & 0.53 & 0.42 & 0.59 \\
Field 4 & 0.86 & 0.93 & 0.87 & 0.92 & 0.83 & 0.90 & 0.76 & 0.79 \\
Overall & 0.79 & 0.85 & 0.84 & 0.98 & 0.69 & 0.76 & 0.63 & 0.70 \\
\hline
\end{tabular}

Table 7: overall accuracy improvement for Fields 1, 2, 3 and 4 following the multitemporal classification. The performance of the multitemporal classification was significantly different (z-value always superior to 5.59 ) in the four classification outputs (March, May, June and July). 